\title{
A protein and mRNA expression-based classification of gastric cancer
}

\author{
Namrata Setia ${ }^{1}$, Agoston T Agoston ${ }^{2}$, Hye S Han ${ }^{1,3}$, John T Mullen ${ }^{4}$, Dan G Duda ${ }^{5}$, \\ Jeffrey W Clark ${ }^{6}$, Vikram Deshpande ${ }^{1}$, Mari Mino-Kenudson ${ }^{1}$, Amitabh Srivastava ${ }^{2}$, \\ Jochen K Lennerz ${ }^{1}$, Theodore S Hong ${ }^{5}$, Eunice L Kwak ${ }^{6, *}$ and Gregory Y Lauwers ${ }^{1, *}$ \\ ${ }^{1}$ Pathology Service, Massachusetts General Hospital, Boston, MA, USA; ${ }^{2}$ Department of Pathology, Brigham \\ and Women's Hospital, Boston, MA, USA; ${ }^{3}$ Konkuk University School of Medicine, Seoul, South Korea; \\ ${ }^{4}$ Department of Surgery, Massachusetts General Hospital, Boston, MA, USA; ${ }^{5}$ Department of Radiation \\ Oncology, Massachusetts General Hospital, Boston, MA, USA and ${ }^{6}$ Department of Medicine, Massachusetts \\ General Hospital, Boston, MA, USA
}

\begin{abstract}
The overall survival of gastric carcinoma patients remains poor despite improved control over known risk factors and surveillance. This highlights the need for new classifications, driven towards identification of potential therapeutic targets. Using sophisticated molecular technologies and analysis, three groups recently provided genetic and epigenetic molecular classifications of gastric cancer (The Cancer Genome Atlas, 'Singapore-Duke' study, and Asian Cancer Research Group). Suggested by these classifications, here, we examined the expression of 14 biomarkers in a cohort of 146 gastric adenocarcinomas and performed unsupervised hierarchical clustering analysis using less expensive and widely available immunohistochemistry and in situ hybridization. Ultimately, we identified five groups of gastric cancers based on Epstein-Barr virus (EBV) positivity, microsatellite instability, aberrant E-cadherin, and p53 expression; the remaining cases constituted a group characterized by normal p53 expression. In addition, the five categories correspond to the reported molecular subgroups by virtue of clinicopathologic features. Furthermore, evaluation between these clusters and survival using the Cox proportional hazards model showed a trend for superior survival in the EBV and microsatellite-instable related adenocarcinomas. In conclusion, we offer as a proposal a simplified algorithm that is able to reproduce the recently proposed molecular subgroups of gastric adenocarcinoma, using immunohistochemical and in situ hybridization techniques.
\end{abstract}

Modern Pathology (2016) 29, 772-784; doi:10.1038/modpathol.2016.55; published online 1 April 2016

Gastric carcinoma is the fifth most common malignancy and the third leading cause of cancer-related death worldwide. Despite better control over known risk factors and development of new chemotherapeutic and targeted agents, in the United States, the 5-year overall survival for gastric cancer patients is only $29 \% .^{1}$ With regard to patient stratification, although several morphologic classifications have been developed, one broadly used system is the Lauren classification, which divides gastric adenocarcinoma into intestinal and diffuse types. ${ }^{2}$ The simple two-tiered classification gives a general understanding of the histogenesis and biology of

Correspondence: Dr GY Lauwers, MD, Department of Pathology, Massachusetts General Hospital, 55 Fruit Street, Warren 2, Boston, MA 02114-2696, USA. E-mail: glauwers@partners.org

${ }^{*}$ ELK and GYL share senior authorship.

Received 6 November 2015; revised 9 February 2016; accepted 10 February 2016; published online 1 April 2016 gastric cancer, and has been particularly helpful in evaluating the epidemiologic data. Another widely used system is the WHO classification, which is based on more precise histologic patterns. It is an all-inclusive system, which recognizes all the rare subtypes that were not identified in the Lauren classification. ${ }^{3}$ Nevertheless, its clinical utility is doubtful as there is little difference in outcomes between the distinct histological subgroups.

Following the successful Trastuzumab for Gastric Cancer (ToGA) trial, the only validated predictive biomarker for personalized therapy of gastric cancer is limited to human epidermal growth factor receptor (Her2) protein expression. ${ }^{4}$ Recently, anti-vascular endothelial growth factor receptor 2 (VEGFR2) antibody (ramucirumab) has been FDA approved, and anti-epidermal growth factor receptor (EGFR) and mesenchymal-epithelial transition factor (MET or 
hepatocyte growth factor receptor therapy) are in clinical development. ${ }^{4}$

Despite ongoing progress, a certain disconnect persists between the morphologic classification schemes and the biology of gastric adenocarcinoma, and, ultimately, the applications of targeted therapies. Recent studies have emphasized the need for new patient stratification strategies that incorporate the emerging molecular classification of gastric cancer and identification of potential therapeutic targets (Table 1). The 'Singapore-Duke' study identified three distinct molecular signatures based on genetic and epigenetic expression of drug-responsive clusters, and subclassified gastric adenocarcinoma into (a) a proliferative subtype characterized by high TP53 mutations and activation of oncogenic pathways, (b) a metabolic subtype with low TP53 mutations and expression of genes characteristic of normal gastric mucosa and metabolic pathways, among other features, and (c) a mesenchymal subtype with low expression of $\mathrm{CDH} 1$ and TP53, increased stem cell marker, and genes characteristic of the epithelial-mesenchymal transition pathway. ${ }^{5}$ The authors commented that the proliferative and mesenchymal types corresponded to Lauren intestinal and diffuse types, respectively. Metabolic-type gastric cancers were highly sensitive to 5-fluorouracil, and the mesenchymal-type gastric adenocarcinomas were more sensitive to phosphatidyl-inositol-3-kinase inhibitors. The Cancer Genome Atlas subdivides gastric cancer based on genetic and epigenetic expression in four pathogenetic pathways: (a) Epstein-Barr virus (EBV) gastric adenocarcinomas characterized by hypermethylation of $C D K N 2 A$, and mutations in PIK3A and PD-L1 expression, (b) microsatelliteinstable high gastric adenocarcinomas with hypermethylation and MLH1 silencing, (c) genomically stable group with $C D H 1$ and $R H O A$ mutations, and (d) chromosomal-instable group corresponding to intestinal histology and a high number of TP53 mutations. ${ }^{6}$ Another recent study from the Asian Cancer Research Group based on gene expression profiling, genome-wide copy number microarrays, and targeted gene sequencing proposed classification of gastric adenocarcinoma into (1) microsatelliteinstable gastric cancer, which present with best overall prognosis and the lowest frequency of recurrence, (2) microsatellite-stable adenocarcinomas

Table 1 Current molecular classifications of gastric cancer ${ }^{\mathrm{a}}$

\section{MOLECULAR CLASSIFICATIONS OF GASTRIC CANCER}

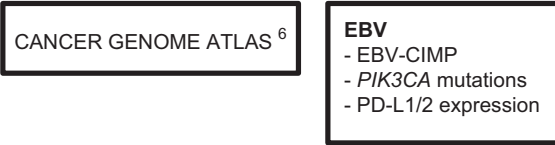

SINGAPORE -DUKE
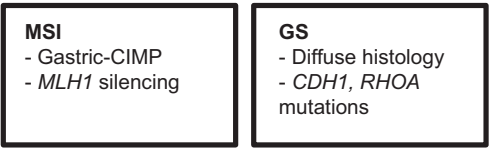

CIN

- Intestinal histology

- TP53 mutations
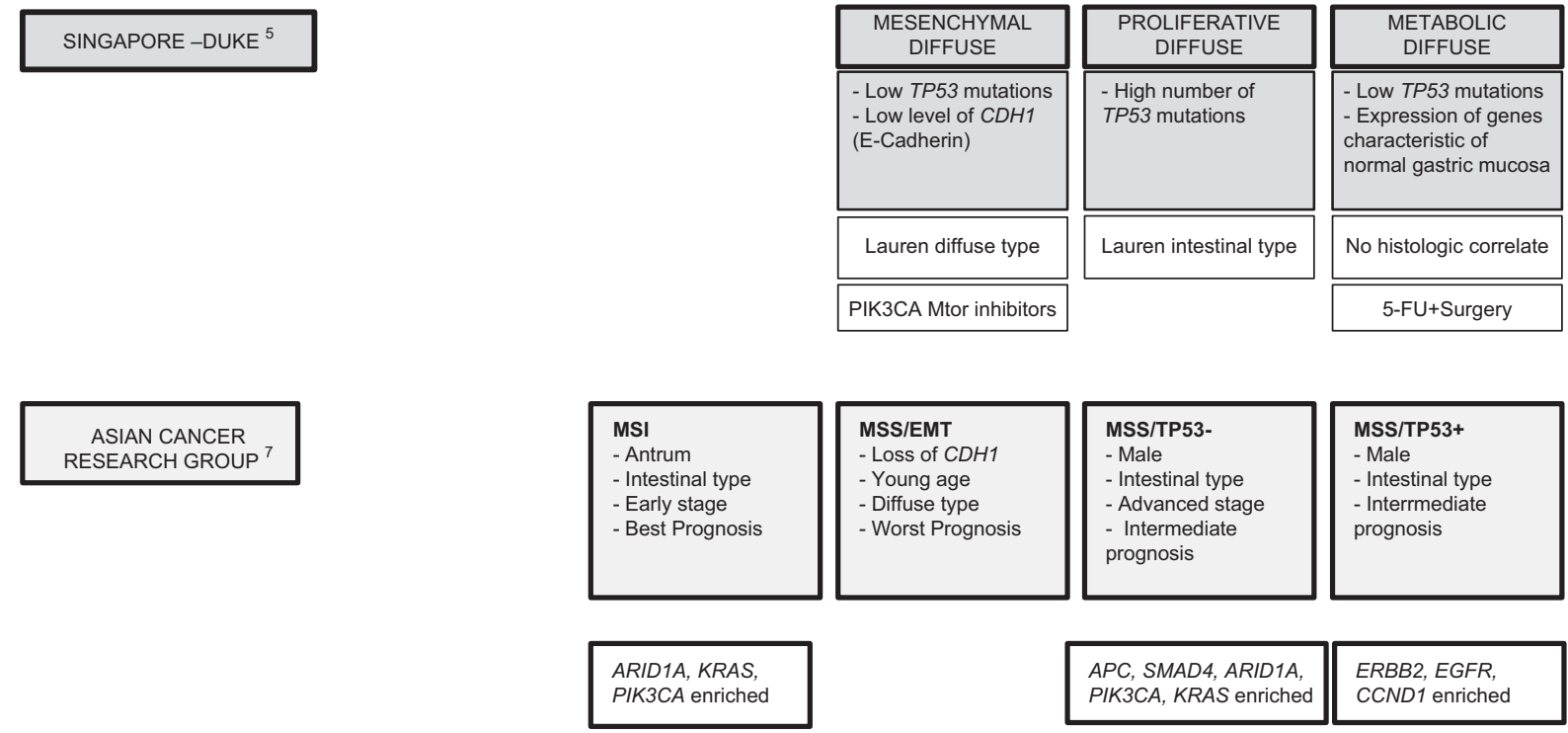

$A P C, S M A D 4, A R I D 1 A$ PIK3CA, KRAS enriched

ERBB2, EGFR CCND1 enriched

Abbreviations: CIN, chromosomal instability; EBV, Epstein-Barr virus; EMT, epithelial-mesenchymal transition; FU, fluorouracil; GS, genomically stable; MSI, microsatellite instability; MSS, microsatellite stable.

aProposed by the 'Singapore-Duke' group, the Cancer Genome Atlas, and the Asian Cancer Research Group. 
with epithelial-mesenchymal transition gene expression signature with the worst prognosis, and (3 and 4) microsatellite-stable adenocarcinomas (with no epithelial-mesenchymal transition gene signature), which are either TP53-active or -inactive adenocarcinomas with intermediate prognosis and recurrence rates. ${ }^{7}$ Although these studies represent a significant progress in defining gastric cancer from a biologic point of view, they were limited either by a lack in clinical scope or the lack of immediate clinical applicability. In fact, to define these subgroups, these studies used multiple advanced molecular techniques including DNA sequencing, RNA sequencing, whole-exome sequencing, copy number variation analysis, and DNA methylation arrays, which are not currently cost effective in practice. Thus, we developed a study with the goal of testing the validity of the three classifications using a series of gastric adenocarcinomas, focusing on protein and mRNA expression and using techniques available in routine diagnostic practice. Furthermore, we attempted to formulate an algorithm to distinguish the molecular subtypes for easy clinical classification and better patient selection for putative targeted therapy.

\section{Materials and methods}

\section{Tissue Samples}

The tissue microarrays (24 cores per slide, $3 \mathrm{~mm}$ each, 1-2 cores per case with 2 controls per slide) were constructed from 146 primary gastric cancer resections performed at Massachusetts General Hospital from 1988 to 2007. The review board at the Massachusetts General Hospital approved this study. Collected clinical and pathologic features include age $(</>70$ years of age, using 70 years (median age)), gender, maximal size $(</>5 \mathrm{~cm}$, using $5 \mathrm{~cm}$ (median)), Lauren type (diffuse, intestinal), TNM stage, tumor grade (grades $1 / 2 / 3 / 4),{ }^{8}$ tumor site (cardia, body/fundus, antrum, multifocal), lymphovascular and/or venous invasion, perineural invasion, and overall survival (months). At least two gastrointestinal pathologists reviewed all H\&E slides (HSH and GYL).

\section{Biomarker Panel}

Expression for 14 different biomarkers was performed and included EBER in situ hybridization, p53, mismatch repair proteins (MLH1, PMS2, MSH2, and MSH6), E-cadherin, PD-L1, MUC2, CDX2, CD10, MUC5AC, MUC6, and HER2. The specifications and dilution, site (membranous, nuclear, and cytoplasmic), scoring criteria, and pattern of staining for all biomarkers are listed in Table 2. Appropriate RNA controls, to assure RNA preservation, were performed on all tissue microarray slides where required. Two gastrointestinal pathologists reviewed all immunohistochemical stains and in situ hybridization (GYL and NS).

\section{Rationale for Biomarker Evaluation}

EBER in situ hybridization is the gold standard to detect EBV status, and localizes the abundantly expressed long noncoding RNAs EBER1 or EBER2 in malignant cells. ${ }^{9,10}$ Use of immunohistochemistry for mismatch repair proteins has a high sensitivity, specificity, and positive and negative predictive value for deficiency of the mismatch repair system. ${ }^{11}$ Additionally, the predominant mechanism of microsatellite instable in gastric cancer is promoter hypermethylation of MLH1 rather than mutations.,12 Several studies have shown an association between aberrant E-cadherin expression and diffuse-type adenocarcinomas, ${ }^{13,14}$ and it has been suggested that loss of E-cadherin is a phenotypic expression of the genetic alteration noted in diffuse-type gastric adenocarcinoma (CDH1 mutations). ${ }^{15}$ Immunohistochemical staining of E-cadherin has been shown to mirror the mRNA expression also. ${ }^{16}$ A disconcordance between the immunostaining of p53 and its mutational status has been reported by several studies; ${ }^{17}$ however, the difference has been reported to decrease if the criteria of overexpression are stringently applied, ${ }^{18}$ as in the current study (Table 2).

\section{Statistics}

The statistical analysis was performed using the $\mathrm{R}$ software for statistical computing v.3.0.2 (http:// www.r-project.org/). Categorical variables were compared with the Fisher's exact test, and $P$-value $<0.05$ (two-sided) was considered statistically significant. The overall survival was measured from the date of resection of the gastric adenocarcinoma to the date of death from any cause (recorded from the medical chart and/or the Social Security death index; http:// www.genealogybank.com/gbnk/ssdi/). The survival data was analyzed by Cox proportional hazards analysis. Unsupervised hierarchical clustering analysis with average linkage algorithms was applied to the data set with the chosen five biomarkers (EBER in situ hybridization, MLH1, PMS2, E-cadherin, and p53), followed by comparison of clinical phenotype and outcome analysis. This was performed using GeneCluster 3.0 (http://www.eisenlab.org/eisen/? page_id =42); TreeView (http://rana.lbl.gov/Eisen Software.htm) was used for graphical representation of the results.

\section{Results}

\section{A Five-Tier Classification of gastric adenocarcinoma}

In accordance with the proposed molecular classifications and based on the results of unsupervised hierarchical clustering analysis of the expression 
Table 2 Diagnostic biomarkers ${ }^{\mathrm{a}}$

\begin{tabular}{|c|c|c|c|c|c|c|}
\hline Biomarker & $\begin{array}{l}\text { Clone and } \\
\text { dilution }\end{array}$ & Cell type & Site & $\begin{array}{l}\text { Score and } \\
\text { criteria }\end{array}$ & Column1 & $\begin{array}{l}\text { Interpreted } \\
\text { as aberrant }\end{array}$ \\
\hline \multirow[t]{2}{*}{ EBER-ISH } & Leica, NA & \multirow[t]{2}{*}{ Tumor } & \multirow[t]{2}{*}{ Nucleus } & 0 & Absent & $\mathrm{N}$ \\
\hline & RTU & & & 1 & Present & $\mathrm{Y}$ \\
\hline \multirow[t]{2}{*}{ MLH1 } & Biocore, E305 & \multirow[t]{2}{*}{ Tumor } & \multirow[t]{2}{*}{ Nucleus } & 0 & Absent & $\mathrm{Y}$ \\
\hline & $1: 50$ & & & 1 & Present & $\mathrm{N}$ \\
\hline \multirow[t]{2}{*}{ PMS2 } & BD MOR4g & \multirow[t]{2}{*}{ Tumor } & \multirow[t]{2}{*}{ Nucleus } & 0 & Absent & $\mathrm{Y}$ \\
\hline & 0.111111111 & & & 1 & Present & $\mathrm{N}$ \\
\hline \multirow[t]{2}{*}{ MSH2 } & Biocore, 25D12 & \multirow[t]{2}{*}{ Tumor } & \multirow[t]{2}{*}{ Nucleus } & 0 & Absent & $\mathrm{Y}$ \\
\hline & $1: 25$ & & & 1 & Present & $\mathrm{N}$ \\
\hline \multirow[t]{2}{*}{ MSH6 } & Biocore 44 & \multirow[t]{2}{*}{ Tumor } & \multirow[t]{2}{*}{ Nucleus } & 0 & Absent & $\mathrm{Y}$ \\
\hline & $1: 25$ & & & 1 & Present & $\mathrm{N}$ \\
\hline \multirow[t]{3}{*}{ P53 } & Leica, DO-7 & \multirow[t]{3}{*}{ Tumor } & \multirow[t]{3}{*}{ Nucleus } & 0 & Complete loss & $\mathrm{Y}$ \\
\hline & RTU & & & 0.5 & Weak, patchy & $\mathrm{N}$ \\
\hline & & & & 1 & Diffuse, strong & $\mathrm{Y}$ \\
\hline \multirow[t]{4}{*}{ E-cadherin } & Leica, 36B5 & \multirow[t]{4}{*}{ Tumor } & \multirow[t]{4}{*}{$\begin{array}{l}\text { Cytoplasmic and } \\
\text { membranous }\end{array}$} & 0 & Complete loss & $\mathrm{Y}$ \\
\hline & RTU & & & 0.33 & Cytoplasmic & $\mathrm{Y}$ \\
\hline & & & & 0.66 & Cytoplasmic and Membranous & $\mathrm{N}$ \\
\hline & & & & 0.99 & Membranous & $\mathrm{N}$ \\
\hline \multirow[t]{3}{*}{ PD-L1 } & $\begin{array}{l}\text { Cell Signaling } \\
\text { EIL3N, } 1: 200\end{array}$ & \multirow[t]{3}{*}{$\begin{array}{l}\text { Tumor and } \\
\text { macrophages }\end{array}$} & \multirow[t]{3}{*}{$\begin{array}{l}\text { Cytoplasmic and } \\
\text { membranous }\end{array}$} & 0 & Absent & $\mathrm{N}$ \\
\hline & & & & 0.5 & $\begin{array}{l}\text { Cytoplasmic or membranous expression } \\
\text { in macrophages }\end{array}$ & $\mathrm{N}$ \\
\hline & & & & 1 & Membranous in tumor cells & $\mathrm{Y}$ \\
\hline \multirow[t]{3}{*}{ MUC2 } & Leica, COP58 & \multirow[t]{3}{*}{ Tumor } & Cytoplasmic & 0 & $<10 \%$ cells positive & $\mathrm{N}$ \\
\hline & 0.180555556 & & & 1 & $10-25 \%$ cells positive & $\mathrm{Y}$ \\
\hline & & & & 2 & $>25 \%$ cells positive & $\mathrm{Y}$ \\
\hline MUC5AC & Leica CCH2, & Tumor & Cytoplasmic & 0 & $<10 \%$ cells positive & $\mathrm{N}$ \\
\hline & 0.111111111 & & & 1 & $10-25 \%$ cells positive & $\mathrm{Y}$ \\
\hline & & & & 2 & $>25 \%$ cells positive & $\mathrm{Y}$ \\
\hline MUC6 & Leica CLH5 & Tumor & Cytoplasmic & 0 & $<10 \%$ cells positive & $\mathrm{N}$ \\
\hline & 0.111111111 & & & 1 & $10-25 \%$ cells positive & $\mathrm{Y}$ \\
\hline & & & & 2 & $>25 \%$ cells positive & $\mathrm{Y}$ \\
\hline CDX2 & Abcam AMT28 & Tumor & Nuclear & 0 & $<10 \%$ cells positive & $\mathrm{N}$ \\
\hline & $1: 25$ & & & 1 & $10-25 \%$ cells positive & $\mathrm{Y}$ \\
\hline & & & & 2 & $>25 \%$ cells positive & $\mathrm{Y}$ \\
\hline CD10 & Leica 56C6 & Tumor & Membranous & 0 & $<10 \%$ cells positive & $\mathrm{N}$ \\
\hline & RTU & & & 1 & $10-25 \%$ cells positive & $\mathrm{Y}$ \\
\hline & & & & 2 & $>25 \%$ cells positive & $\mathrm{Y}$ \\
\hline Her2 & Ventana SP3 & Tumor & Membranous & 0 & $\begin{array}{l}\text { No reactivity, or membranous reactivity } \\
\text { in }<5 \text { clustered tumor cells }\end{array}$ & $\mathrm{N}$ \\
\hline & 1:08 & & & 1 & $\begin{array}{l}\text { Tumor cell cluster ( } \geq 5 \text { cells) with a faint/ } \\
\text { barely perceptible membranous } \\
\text { reactivity }\end{array}$ & $\mathrm{N}$ \\
\hline & & & & 2 & $\begin{array}{l}\text { Weak-to-moderate complete, basolateral } \\
\text { or lateral membranous reactivity in } \\
\text { tumor cell cluster ( } \geq 5 \text { cells) }\end{array}$ & $\mathrm{N}$ \\
\hline & & & & 3 & $\begin{array}{l}\text { Tumor cell cluster ( } \geq 5 \text { cells) with a } \\
\text { strong complete, basolateral or lateral } \\
\text { membranous staining }\end{array}$ & $\mathrm{Y}$ \\
\hline
\end{tabular}

Abbreviations: NA, not available; RTU, ready to use.

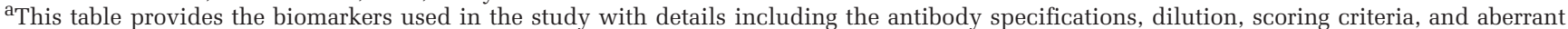
pattern of staining. 
EBV in situ hybridization, mismatch repair proteins, E-cadherin, and p53, a five-tier classification algorithm of gastric cancer was generated. Out of the cohort of 146 cases, EBER-positive gastric cancers constituted $5 \%$ of the cases $(n=7)$ (Cluster 1$)$; mismatch repair-deficient gastric adenocarcinomas represented $16 \%$ of the cases $(n=24)$ (Cluster 2); aberrant expression of E-cadherin (Cluster 3) was noted in $21 \%$ of the gastric cancers $(n=30)$; and adenocarcinomas with aberrant p53 expression (Cluster 4) represented $51 \%$ of the cases $(n=71)$. Cluster 4 with aberrant p53 expression was further subclassified into intestinal (33\%, 25/75, MUC2 and/ or CD10 positive), gastric (32\%, 24/75, MUC5AC and/or MUC6 positive), mixed (15\%, 11/75, both MUC2 and/or CD10 positive and MUC5AC and/or MUC6 positive), and null (20\%, 15/75, MUC2, CD10, MUC5AC and MUC6 negative) subclusters. The remaining cases with normal p53 expression were designated as Cluster 5, comprising $7 \%$ of gastric cancers $(n=10)$. Figure 1 depicts the biomarkers expression-based clusters along with key clinicopathologic features. Figure 2 presents the proteinbased expression.

\section{Clinicopathological Features of the Five Subtypes of Gastric Cancers}

EBV-positive gastric cancer (Cluster 1). See clinical characteristics in Table 3. The lesions were characterized by prominent lymphoid infiltrate in all cases (Figure 3). EBV-positive gastric adenocarcinomas trended towards a better survival $(P=0.15$, CI: 0.14-1.36, HR 0.43 median survival 264 vs 29 months for non-EBV gastric cancer, Figure 4); however, the difference was not statistically significant. A strong correlation with membranous expression of PD-L1 in tumor cells was seen $(57 \%$ vs $0 \%, P=0.001)$ (Figure 3).

Microsatellite-instable gastric cancers (Cluster 2). See clinical characteristics in Table 3. There was a significant association with MUC2 expression (8/24 $(33 \%)$ in this cluster compared with the rest of the cohort $18 / 122(15 \%), P=0.04)$. This cluster had a lower frequency of lymph node metastasis (lymph node stage category $>\mathrm{N} 1,27 \%$ microsatellite-instable adenocarcinoma vs 55\% non-microsatellite-instable gastric cancer, $P=0.02$, CI: 0.09-0.91), and the patients trended toward better survival ( $P=0.09$, CI: 0.32-1.09, HR 0.59, median survival: 56 vs 27 months for nonmicrosatellite- instable gastric cancer; Figure 4). The loss of MLH1 and PMS2 was the predominant pattern (95.8\%); an additional case showed loss of PMS2 only (4.16\%) (Figure 5).

Gastric cancers with aberrant E-cadherin expression (Cluster 3). See clinical characteristics in Table 3. The gastric cancers were predominantly of the poorly cohesive (ie, diffuse) type (27/30, 90\%). This group was subdivided into Cluster 3A showing complete loss of E-cadherin (40\%) and Cluster 3B with cytoplasmic granular E-cadherin (60\%) staining (Figure 6). The patients of Cluster 3 had significantly lower aberrant p53 expression (16/30, 53\%) VS $91 / 114(80 \%)$ in the remainder $(P=0.004)$. The difference was more significant in subcluster $3 \mathrm{~B} v \mathrm{Vs}$ the remainder $(7 / 18(39 \%)$ in $3 \mathrm{~B}$ vs $100 / 126(79 \%)$ in the remainder, $P=0.0007)$. The patients in $3 \mathrm{~B}$ also

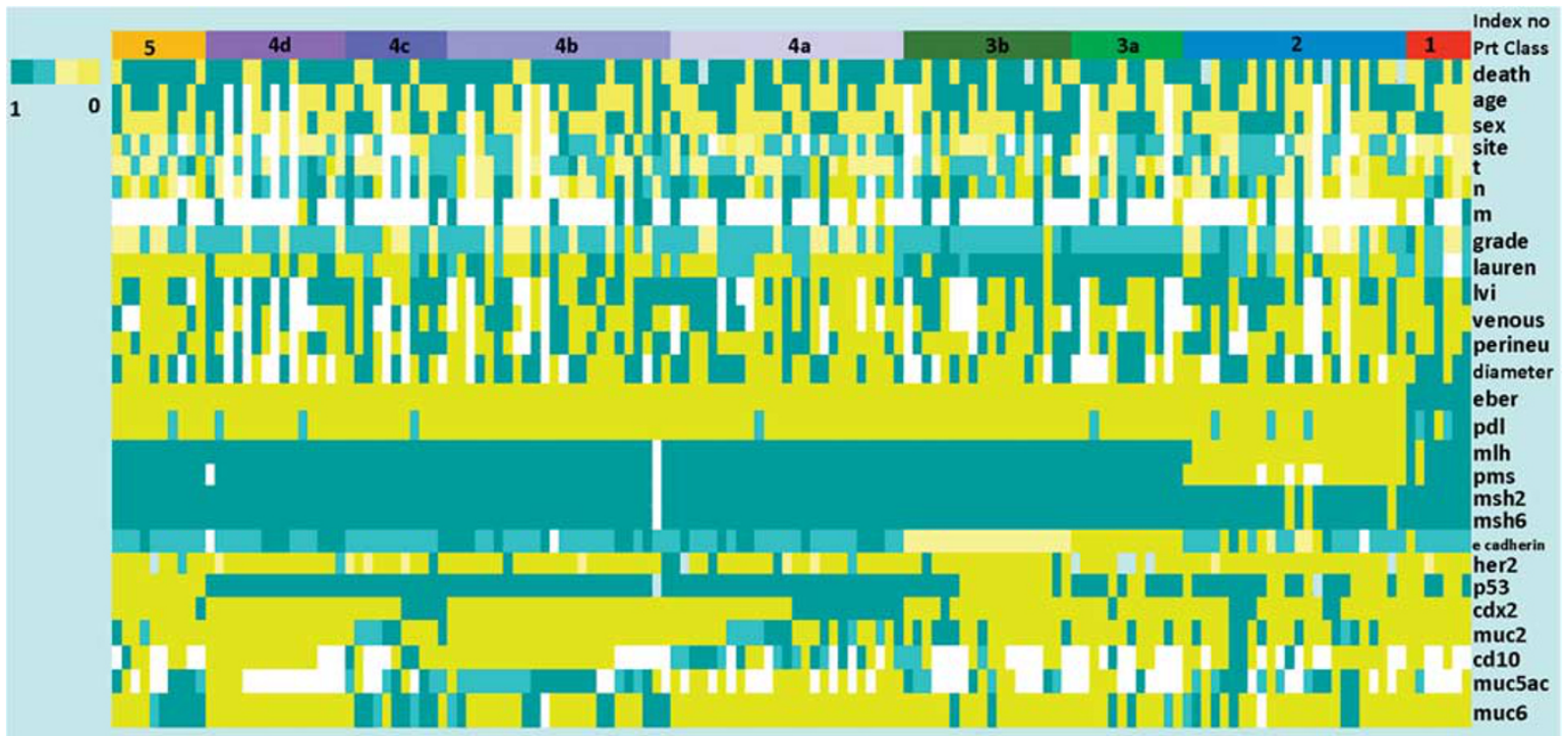

Figure 1 Heat map depicting clinicopathologic features and biomarker results for the cohort. Cluster analysis of 146 cases, which are represented in the columns and the clinicopathologic features and biomarkers (ie, variables studied) in the rows. The variables are shown on the right. Aberrantly expressed variables in the cohort are shown in progressively brighter shades (blue to yellow) depending on the fold difference. Variables shown in white were not available for interpretation. 
Table 3 Clinicopathologic characteristics of the various gastric cancer subtypes

\begin{tabular}{|c|c|c|c|}
\hline & Mean age (in years) & $M: F$ ratio & Site (ratio) \\
\hline EBV-positive gastric cancers & $65 \pm 10$ & $1.3: 1$ & Antrum:non-antrum: 0:7 ${ }^{\mathrm{a}}$ \\
\hline Microsatellite-instable gastric cancers & $68 \pm 15$ & $1.3: 1$ & Cardia:non-cardia: $1: 5.3^{\mathrm{b}}$ \\
\hline Gastric cancers with aberrant E-cadherin expression & $67 \pm 15$ & $1.6: 1$ & Cardia:non-cardia: $1: 3^{\mathrm{C}}$ \\
\hline Gastric cancers with aberrant p53 expression & $68 \pm 12$ & $1.5: 1$ & Antrum:non-antrum: $1: 1.2^{\mathrm{d}}$ \\
\hline Gastric cancers with normal p53 expression & $66 \pm 15$ & $2.3: 1$ & Body:non-body: 1:1 \\
\hline
\end{tabular}

Abbreviation: EBV, Epstein-Barr virus; F, female; M, male.

${ }^{a}$ Ratio is $1: 1.15$ in other groups $(P=0.02)$.

${ }^{b_{R}}$ atio is $1: 4.05$ in other groups $(P=0.762)$

${ }^{C}$ Ratio is $1: 4.5$ in other groups $(P=0.53)$.

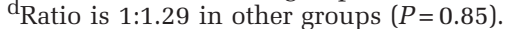

Ratio is $1: 2.6$ in other types $(P=0.287)$.

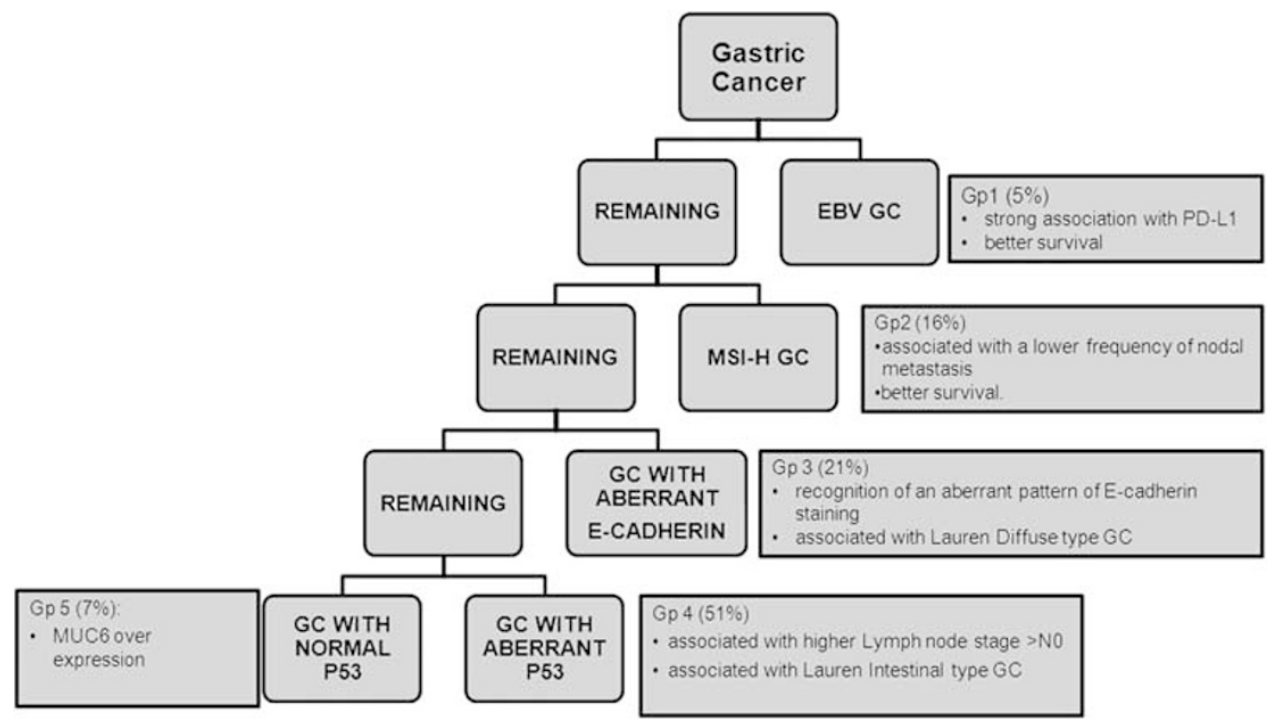

Figure 2 Summary of protein expression-based classification. The hierarchical clustering resulted in the determination of five groups of gastric adenocarcinomas. EBV, Epstein-Barr virus; GC, gastric cancer; MSI-H, high microsatellite instability.

were older than 3A (3A: $62.4 \pm 16.69$ years, $30 \%>70$ years; 3B: $71.4 \pm 11.86$ years, $65 \%>70$ years). There was no survival difference $(P=0.57$, CI: $0.71-1.88$, HR 1.15, median survival: 15 vs 36 months for the remaining gastric adenocarcinomas; Figure 4) in this group.

Gastric cancers with aberrant p53 expression (Cluster 4). See clinical characteristics in Table 3. The tumors were predominantly of intestinal type $(61 / 76,81 \%)$. The lesions were associated with higher lymph node stage $>$ No $(P=0.03$, CI: $1.06-6.24,81 \%$ vs $63 \%$ in the remaining adenocarcinomas). This cluster trended towards increased Her2 staining (Her2 $>0, P=0.05$, CI: 0.97-11.34, $20 \%$ vs $8 \%$ in the remaining cases). No significant survival difference was noted in this group $(P=0.13$, CI: $0.92-2.03$, HR 1.36, median survival 27 vs 38 months in the remaining adenocarcinomas; Figure 4).
Based on the pattern of MUC and CD10 expression, this cluster was subdivided into four subgroups (intestinal (MUC2 \pm CD10); gastric (MUC5AC \pm MUC6); mixed (MUC2 \pm CD10 and MUC5AC \pm MUC6); and null (MUC2-CD10-, MUC5AC-, and MUC6-) subgroups) (Figures 7 and 8). Intestinal and mixed adenocarcinomas trended towards increased Her2/neu expression (intestinal phenotype adenocarcinoma: Her2 $>0, P=0.10$, CI: $0.60-13.40,17 \%$ vs $6 \%$; mixed phenotype cancer: Her2 $>0, P=0.05$, CI: 0.76-17.70, $36 \%$ vs $13 \%$ ). Null-type cancer were associated with higher frequency of nodal metastasis $>$ No $(P=0.03$, CI: $1.03->10^{3}, 100 \%$ vs $69 \%$ in the remaining cases). Those were also associated with a significantly higher percentage of lymphovascular invasion $(P=0.01$, CI: $1.35->10^{3}, 100 \%$ vs $\left.61 \%\right)$. There was no survival difference between the subcategories.

Gastric adenocarcinomas with normal p53 expression (Cluster 5). The remaining cancers $(7 \%$ of cases with normal p53 expression) constituted 

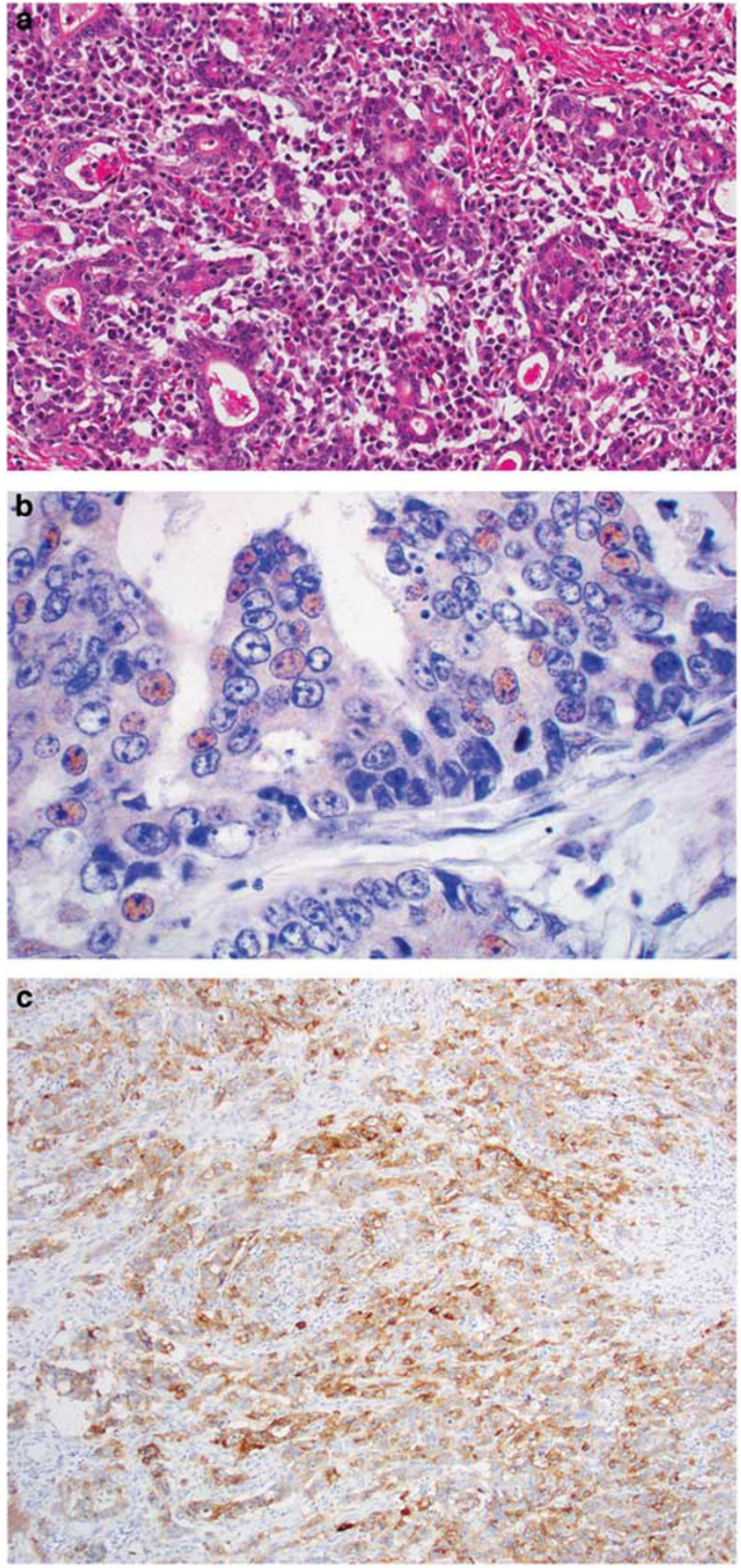

Figure 3 Epstein-Barr virus (EBV)-associated gastric Carcinoma. (a) The neoplasm displays a prominent lymphoid infiltrate. (b) EBV-encoded RNA in situ hybridization showing specific (brown) transcripts in the neoplastic nuclei. (c) EBV-associated gastric carcinoma showing strong membranous expression of PD-L1 (immune-checkpoint pathway protein, programmed death ligand).

Cluster 5. Observed in this group were a lack of EBV in situ hybridization, mismatch repair deficiency and aberrant E-cadherin expression. See clinical characteristics in Table 3. Morphologically, all 10 cases presented a gland-forming (ie, intestinal) morphotype. This cluster was associated with an

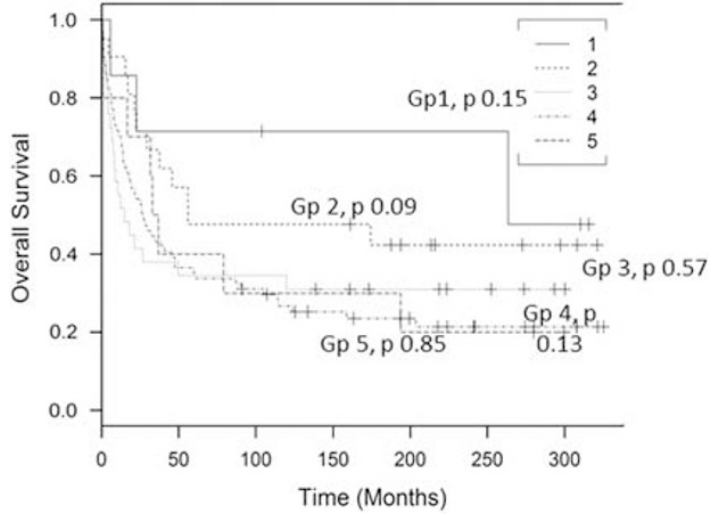

Figure 4 Kaplan-Meier curves for gastric cancer survival according to protein expression-based classification.

increased expression of MUC6 $(P=0.01, \mathrm{CI}: 1.23-$ $28.88,60 \%$ vs $21 \%$ ). There was no survival difference $(P=0.84$, CI: $0.52-2.22$, HR 1.08 , median survival 35 vs 29 months for the remaining cases (Figure 4).

\section{Discussion}

We hereby propose a biomarker expression-based classification of gastric adenocarcinomas that parallel the recently recognized genetic classifications of gastric cancer. ${ }^{5-7}$ Hierarchical clustering resulted in the determination of the four main groups, and while these groups are not entirely mutually exclusive, an algorithm for their diagnostic distinction is provided (Figures 1 and 2).

In our cohort, we found a lower incidence of EBV gastric cancers $(5 \%)$ compared with the the Cancer Genome Atlas $^{6}(8.8 \%)$ and other publications $(2-20 \%) .{ }^{9}$ However, another study showed a similar frequency of $5.1 \%{ }^{19}$ The mechanism of EBV carcinogenesis is a genome-wide DNA methylation. The process involves a series of tumor suppressor genes (eg, p14, p15, p16, APC, CDH, MGMT and PTEN), which result in uncontrolled cell growth. ${ }^{20,21}$

Of note, although microsatellite-instable gastric adenocarcinomas are also associated with hypermethylation and silencing of genes (and their promoters) in a distinctive pattern. EBV gastric cancers having a more extensive pattern of methylation of promoter and non-promoter CpG islands. ${ }^{22} \mathrm{In}$ fact, EBV gastric cancers are almost exclusive of the microsatellite-instable phenotype. ${ }^{6,23-25}$ A series of characteristics are important to underscore; EBV gastric cancers lack $R H O A$ mutations $;{ }^{6,23,24}$ however, a decreased expression of $R H O A$ (and $C D H 1$ ) may be seen secondary to hypermethylation of the gene or its promoter. ${ }^{23,24,26,27}$ They also show a lack of TP53 mutations. $6,23,24,28,29$ This trend was also recorded in the Asian Cancer Research Group data set. ${ }^{7}$ It has been suggested that the profound global DNA effects are responsible for the distinctive clinicopathologic 

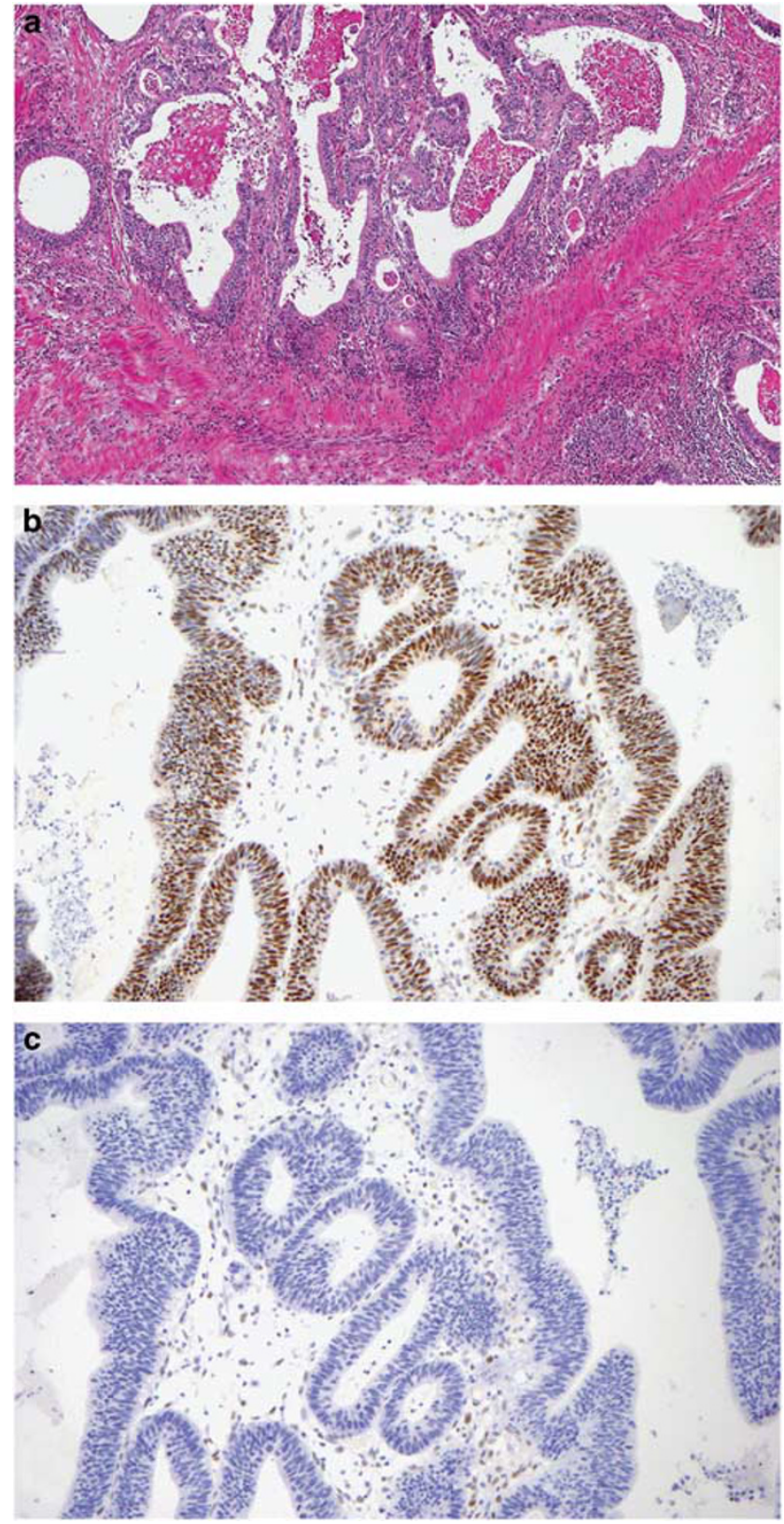

Figure 5 Microsatellite-instable gastric carcinoma showing intestinal phenotype (a), with aberrant overexpression of p53 (b) and loss of MLH1 protein (c). PMS2 was also lost in the tumor cells (not show); however, MSH2 and MSH6 proteins were retained.

features of EBV gastric cancers ${ }^{20}$ including male predominance $^{9,30}$ and proximal location. ${ }^{31}$ Notably, the purported younger age has not been confirmed by recent analysis. ${ }^{19,32}$ In the current study, we confirmed the non-antral location. A trend for younger $(<70$ years $)$ male patients was seen; however, the difference was not statistically significant. A prominent lymphoid infiltrate was seen in all cases, which is consistent with prior studies. ${ }^{33}$ This group also had trend towards better survival, consistent with the reported literature. ${ }^{23,32,34-36}$
A significant association with the immunecheckpoint pathway protein programmed death ligand (PD-L1) was seen in the EBV gastric cancer cluster. Similar findings have been noted at genomic levels with amplification of the 9p24.1 locus, which includes the CD274 gene (encoding for PD-L1). ${ }^{6,24}$ The prognostic significance of this finding is unclear currently. Nevertheless, it suggests a potential role for immunotherapy with anti-PD-1/PD-L1 monoclonal antibodies augmenting antitumor immune response.

Microsatellite-instable gastric adenocarcinomas have been recognized previously as a distinct group based on clinicopathologic ${ }^{37}$ and molecular findings. ${ }^{6,38}$ However, aberrant E-cadherin or p53 expression may be seen in this subgroup, with hypermethylation of $\mathrm{CDH}^{27}$ and abnormalities in TP53 (most frequently as a result of loss of heterozygosity). ${ }^{39}$ There is no prognostic significance to these findings, allowing the present segregation strategy. The frequency of microsatelliteinstable gastric adenocarcinoma in our cohort was $16 \%$ vs $21.7 \%$ in the Cancer Genome Atlas ${ }^{6}, 22.7 \%$ in the Asian Cancer Research Group, ${ }^{7}$ and 8-25.9\% in the literature. ${ }^{40-42}$ The reported incidence is higher in western studies ${ }^{43}$ and associated with older age, female gender, larger tumor size, intestinal differentiation, and lower rate of nodal involvement. ${ }^{40,44}$ In the Asian Cancer Research Group, the microsatellite-instable subtype was predominantly associated with antral location, early stage, and intestinal phenotype as well. ${ }^{7}$ We confirmed the association with intestinal differentiation as established by MUC2 positivity (rather than the Lauren intestinal morphotype) and lower frequency of nodal metastasis. This observation is also reflective of lesser biologic aggressiveness and a trend towards longer survival in this group. Consistent with prior studies, loss of MLH1 and PMS2 was the predominant pattern. ${ }^{40,45}$ The mechanism is predominantly hypermethylation of MLH1 promoter $^{6,46}$ and, less commonly, mutations in MLH1 and MSH2. ${ }^{46}$ Notably, mismatch repair deficiency and TP53 mutations are not mutually exclusive carcinogenic pathways. Similar observations have been noted in prior studies of gastric adenocarcinoma. ${ }^{39}$

After exclusion of the EBV and microsatelliteinstable clusters, we identified a distinct subgroup of cases, characterized by aberrant E-cadherin expression. A few studies have reported TP53 mutations as a late event in the development of poorly cohesive gastric cancer, which was our rationale for using cases of 'gastric cancer with aberrant E-cadherin expression' before 'gastric cancer with aberrant p53 expression' to assign a group for clinical applicability. ${ }^{47,48}$ The frequency of this subset best correlates with the gastric cancer-stable group (genomically stable) reported in the Cancer Genome Atlas, ${ }^{6}$ and the microsatellite stable/epithelial-mesenchymal transition subtype of the Asian Cancer Research Group. ${ }^{7}$ This group 

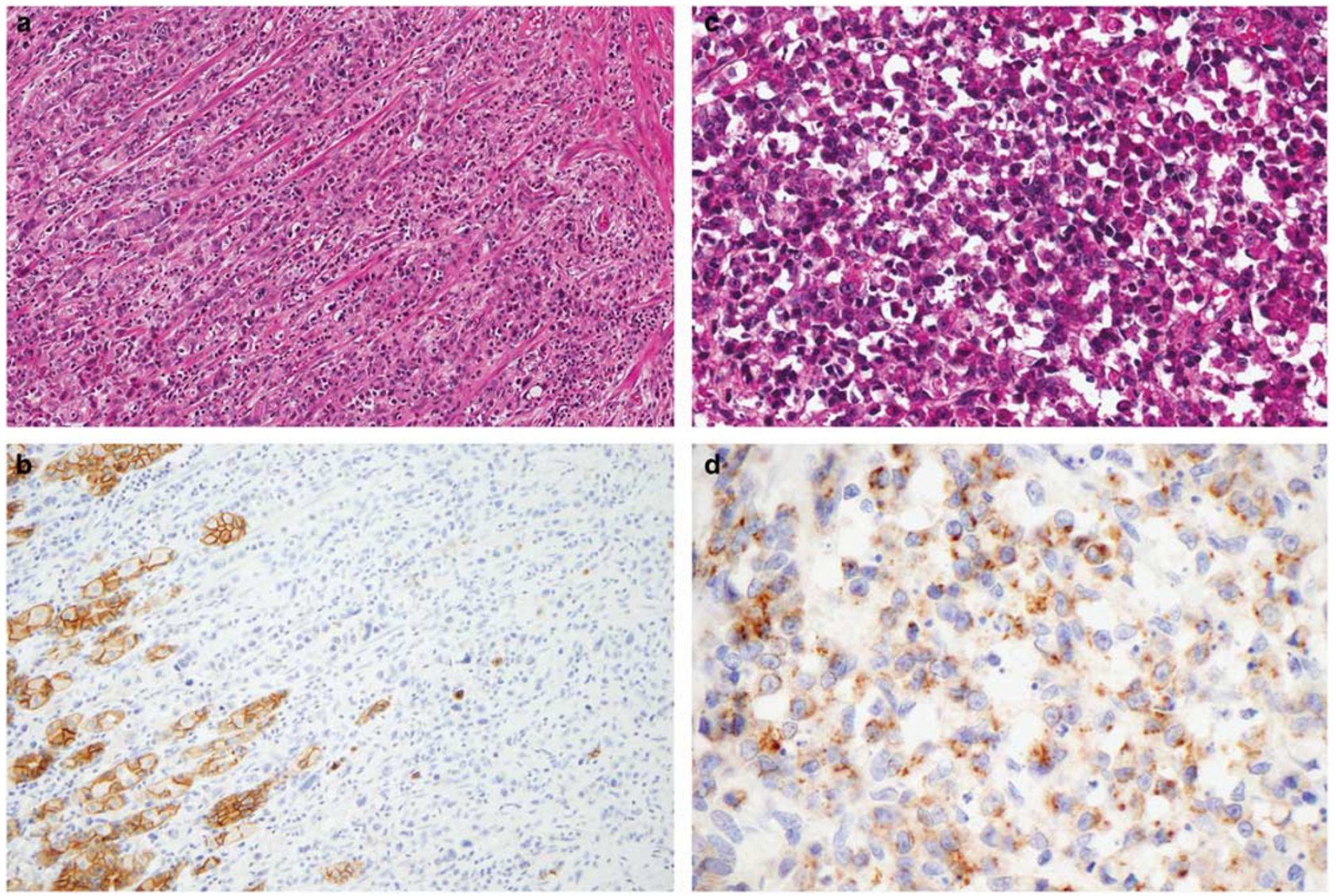

Figure 6 Aberrant E-cadherin-associated gastric carcinoma. (a and b) Complete loss of E-cadherin protein is noted in this diffuse-type/ poorly cohesive adenocarcinoma. (c and $\mathbf{d}$ ) These pictures depict granular/dot-like expression of E-cadherin protein in a poorly cohesive adenocarcinoma.

\begin{tabular}{|l|l|l|l|l|l|}
\hline & MUC2 + & CDX2 + & CD10+ & MUC5AC+ & MUC6+ \\
\hline MUC2+ & & intestinal & intestinal & hybrid & hybrid \\
\hline CDX2+ & intestinal & & intestinal & hybrid & hybrid \\
\hline CD10+ & intestinal & intestinal & & hybrid & hybrid \\
\hline MUC5AC+ & hybrid & hybrid & hybrid & & gastric \\
\hline MUC6+ & hybrid & hybrid & hybrid & gastric & \\
\hline
\end{tabular}

Figure 7 Interpretation of subcharacterization of Cluster 4 based on immunophenotype. Not included is 'null phenotype,' which is MUC2 - , CDX2 - , CD10 - , MUC5AC - , MUC6 - .

constituted $21 \%$ of the entire cohort similar to the $20 \%$ and $15.3 \%$ reported in these studies. The histologic Lauren diffuse type, observed in this group (90\% diffuse type), is comparable to the so-called mesenchymal group of Lei et $a l^{5}$ (seen in $73 \%$ diffuse type). An enrichment of mutations in $\mathrm{CDH} 1$ has been noted in $37 \%$ of the genomically stable group; and an additional $30 \%$ of the cases had either RHOA or CLDN18-affecting RHOA or ARHGAP's regulation of RHOA and/or cell motility. ${ }^{6}$ Of note, activated $R H O A$ has been reported to act through effectors, including
ROCK1, with resultant activation of STAT3, whose expression has been linked to aberrant E-cadherin expression in diffuse-type gastric cancers. ${ }^{49,50}$ Although not confirmed, it is likely that genetic and epigenetic changes in both $C D H 1$ and $R H O A$ would result in decreased expression of E-cadherin protein. Of interest, Lei et $a l^{5}$ demonstrated a low level of expression of E-cadherin and p53, similar to our group, in their mesenchymal subgroup. Furthermore, it is worth mentioning that $\mathrm{CDH1}$ and $\mathrm{RHOA}$ mutations were not as prevalent in the microsatellite- 

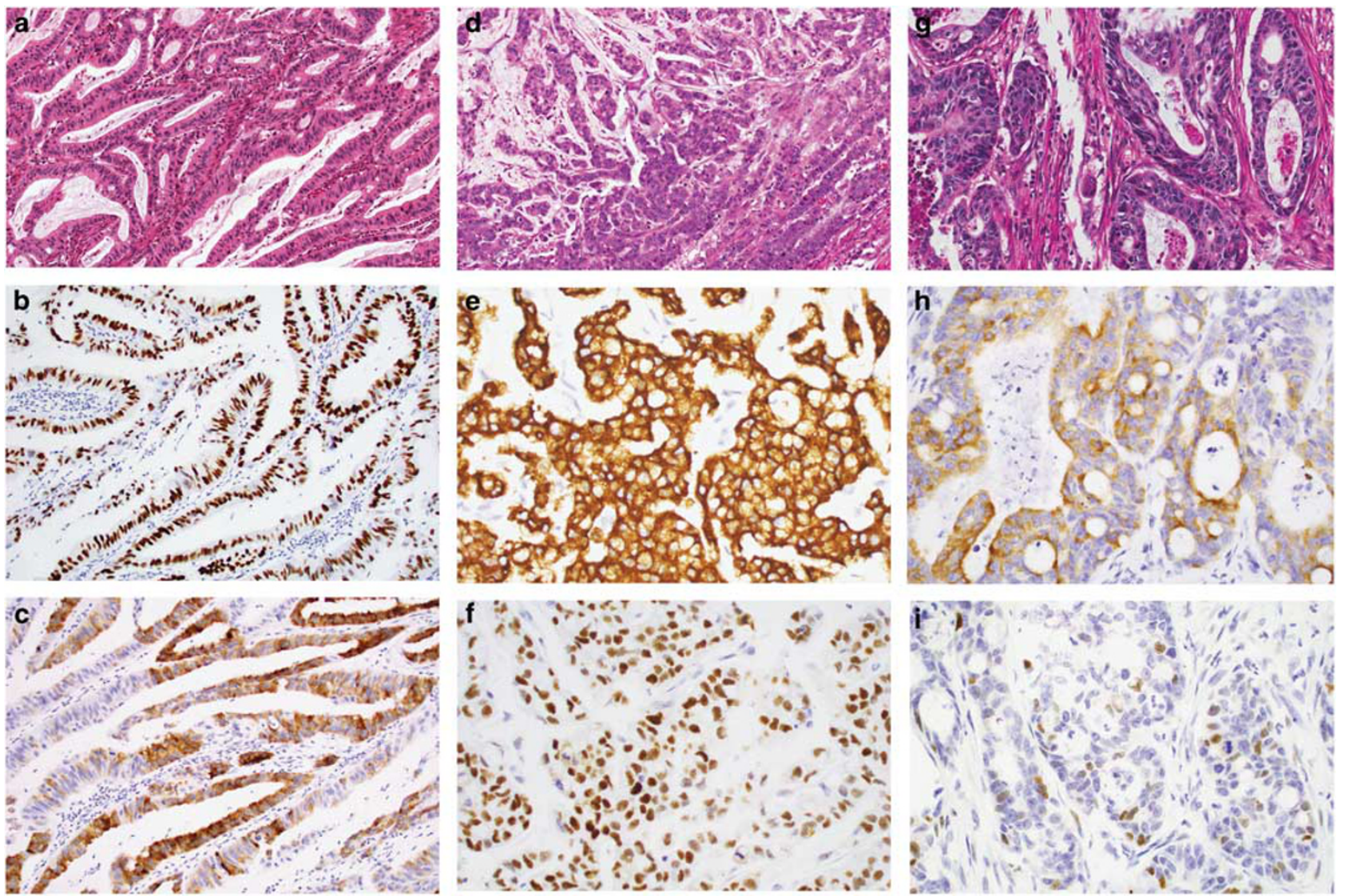

Figure 8 Gastric carcinoma of various phenotype: gastric phenotype, Cluster 4 (a, $\mathbf{h}$, and $\mathbf{e})$ showing overexpression of p53 protein (b) and cytoplasmic expression of MUC6 protein (c). Intestinal phenotype, Cluster 4 (d, h, and e) showing cytoplasmic expression of MUC2 protein (e) and overexpression of p53 protein (f). Another example with intestinal phenotype, Cluster 5 (g, h, and e) with cytoplasmic expression of MUC6 protein (h) but normal pattern of p53 protein (i).

stable/epithelial-mesenchymal transition subtype of Asian Cancer Research Group compared to the The Cancer Genome Atlas. ${ }^{6,7}$

Given the amplification of gastric stem cell markers seen in the mesenchymal subtype, a role for preferential sensitivity to PI3K-AKT-mTOR inhibitors has been suggested. ${ }^{5} \mathrm{CDH} 1$ and $\mathrm{RHOA}$ signaling pathway's dysfunction has been reported in this subgroup; inhibition of RhoA activity by using an inhibitor of Rho-associated kinase (ROCK), which is an effector protein of RhoA, has been shown to induce apoptosis of gastric cancer cells. ${ }^{51} \mathrm{~A}$ recent study demonstrated a decrease in epithelialmesenchymal transition (increased expression of E-cadherin and decreased expression of N-cadherin) with danusertib (potent pan-Aurora kinase). The drug also inhibits the PI3K/Akt/mTOR-mediated signaling pathway in human gastric cancer cells. ${ }^{52}$

Another interesting finding was the aberrant cytoplasmic expression of E-cadherin. Prior studies refer to this as 'heterogeneous aberrant staining' ${ }^{53}$ or "paranuclear staining. ${ }^{54}$ It has been suggested that mutation of exon 8 of $C D H 1$ expresses an abnormal E-cadherin protein that lacks the appropriate signals for post-translational modifications, which permit the normal transport to the cell membrane and glycosylation of E-cadherin; this results in the arrest of E-cadherin in the Golgi apparatus. ${ }^{53,55}$ In another report, cytoplasmic E-cadherin was present in a gastric adenocarcinoma with a 5-bp insertion in exon $9 .{ }^{56}$ The significance of a lower aberrant p53 expression $(39 \%$ vs $75 \%)$ in the two subclusters (cytoplasmic vs complete loss of E-cadherin) is unclear. Furthermore, there was no difference in the clinicopathologic features or survival other than a trend towards older age in the subset with cytoplasmic expression.

The cluster with aberrant p53 expression formed the majority of cases (51\%), and is concordant with the chromosomal instability group $(50 \%)$ of the Cancer Genome Atlas $^{6}$, the proliferative subtype $(45 \%)$ of Lei et $a{ }^{5}{ }^{5}$ and the microsatellite-stable/ TP53 type of the Asian Cancer Research Group (35.7\%). ${ }^{7}$ A strong correlation with Lauren intestinal morphotype (81\%) was seen, supporting this group's correspondence to chromosomal instability $(84 \%)^{6}$, proliferative type $(75 \%),{ }^{5}$ and microsatellite-stable/ TP53 type $(85.1 \%){ }^{7}$ A higher lymph node stage was observed, as has been reported previously in gastric cancers with TP53 mutations. ${ }^{57-61}$ A trend towards 
increased Her2/neu was also noted; however, the overall frequency of Her2/neu positivity was low, which may be attributed to an overall lower percentage of Lauren intestinal-type cancers (49\%) in our cohort, in comparison with the ToGA trial where intestinal-type constituted 91\% of tumors. ${ }^{62}$

For gastric adenocarcinomas with aberrant p53, potential targets include the blockade of receptor tyrosine kinases (ie, HER2, EGFR, VEGFR, c-MET, and fibroblast growth factor receptor 2, and cellcycle mediators (CCNE1, CCND1 and CDK6)), which are amplified in this group. ${ }^{6}$

The features of the group with normal p53 expression and increased MUC6 expression likely correspond to the metabolic subtype reported by Lei et $a .^{5}$ This group has been related to the spasmolytic polypeptide-expressing metaplasia pathway, owing to the overexpression of genes characteristic of normal gastric mucosa. Of note, the metabolic subtype is highly sensitive to 5-fluorouracil owing to significantly lower expression of both thymidylate synthase and dihydropyrimidine dehydrogenase..$^{5}$ A limitation of our study is the lack of corresponding genetic and epigenetic data for the cohort, which may result in some misclassification of the tumors. However, the fact that we have upregulation or lack of expression of the key proteins corresponding to the reported molecular classifications of gastric cancer (eg, increased expression of EBER by in situ hybridization, loss of MLH1, loss of E-cadherin and aberrant p53) suggests that the error may be minimal. This classification algorithm was also independently verified by hierarchical clustering analysis. Admittedly, although improved survival trends were noted in some subgroups, we also did not observe statistically significant survival differences within the subgroups; a likely consequence of the limited number of cases in some subgroups and an observation that ought to be tested in larger studies.

As the prognosis of gastric adenocarcinoma remains dismal despite improving surgical and adjuvant therapies, recent advances in genomic technologies have paved the way toward understanding the molecular underpinning of gastric cancers and the identification of therapeutic biomarkers that influence outcomes and guide management strategies. However, to date, in clinical practice, gastric adenocarcinomas remain essentially classified histologically, as access and cost of high-throughput genomic technologies may limit universal molecular fingerprinting of all gastric cancers. In this study, taking into account of the results of recently developed genetic and epigenetic molecular classifications of gastric adenocarcinomas, we demonstrate that in situ hybridization and immunohistochemical characterization of tumors can appropriately identify tumor subgroups similar to genomic profiling and could be an alternative in guiding targeted therapies. Nevertheless, this proposal necessitates validation. First, given that we have only assessed up to two cores per case, the issue of intratumoral heterogeneity needs to be evaluated. Second, the sensitivities and specificities of the immunohistochemical markers need to be explored. Finally, given that immunohistochemistry is a non-quantitative method and that quantitative molecular testing alternatives are readily available (eg, qRT-PCR), such assays should be evaluated as an alternative, although more expensive technology.

\section{Disclosure/conflict of interest}

The authors declare no conflict of interest.

\section{References}

1 National Cancer Institute. Surveillance, Epidemiology, and End Results (SEER) Program (www.seer.cancer. gov) Research Data (1973-2012). National Cancer Institute, DCCPS, Surveillance Research Program, Surveillance Systems Branch, released April 2015, based on the November 2014 submission (www.seer. cancer.gov); last accessed on July 2015.

2 Lauren P. The two histological main types of gastric carcinoma: diffuse and so-called intestinal-type carcinoma. an attempt at a histo-clinical classification. Acta Pathol Microbiol Scand 1965;64:31-49.

3 Lauwers GY, Carneiro F, Graham DY et al. Gastric carcinoma. In: Bosman FT, Carneiro F, Hruban RH, Theise ND (eds). WHO Classification of Tumours of the Digestive System, 4th edn. IARC Press: Lyon, France, 2010, pp 48-58.

4 Sunakawa Y, Lenz HJ. Molecular classification of gastric adenocarcinoma: translating new insights from the cancer genome atlas research network. Curr Treat Options Oncol 2015;16:17; 331-015-0331-y.

5 Lei Z, Tan IB, Das K et al. Identification of molecular subtypes of gastric cancer with different responses to PI3-kinase inhibitors and 5-fluorouracil. Gastroenterology 2013;145:554-565.

6 Cancer Genome Atlas Research Network. Comprehensive molecular characterization of gastric adenocarcinoma. Nature 2014;513:202-209.

7 Cristescu R, Lee J, Nebozhyn M. Molecular analysis of gastric cancer identifies subtypes associated with distinct clinical outcomes. Nat Med 2015;21:449-456.

8 Edge SB, Byrd DR, Carducci MA et al (eds). AJCC Cancer Staging Manual, 7th edn, Chapter 11. Springer: New York, NY, USA, 2009, pp 117-121.

9 Shinozaki-Ushiku A, Kunita A, Fukayama M. Update on Epstein-Barr virus and gastric cancer (review). Int J Oncol 2015;46:1421-1434.

10 Gulley ML, Tang W. Laboratory assays for Epstein-Barr virus-related disease. J Mol Diagn 2008;10:279-292.

11 Chiaravalli AM, Cornaggia M, Furlan D et al. The role of histological investigation in prognostic evaluation of advanced gastric cancer. analysis of histological structure and molecular changes compared with invasive pattern and stage. Virchows Arch 2001;439: 158-169.

12 Pinto M, Wu Y, Mensink RG et al. Somatic mutations in mismatch repair genes in sporadic gastric carcinomas are not a cause but a consequence of the mutator 
phenotype. Cancer Genet Cytogenet 2008;180: 110-114.

13 Gabbert HE, Mueller W, Schneiders A et al. Prognostic value of E-cadherin expression in 413 gastric carcinomas. Int J Cancer 1996;69:184-189.

14 Blok P, Craanen ME, Dekker W et al. Loss of E-cadherin expression in early gastric cancer. Histopathology 1999;34:410-415.

15 Carneiro F, Machado JC, Seruca R et al. E-cadherin changes in gastric carcinoma. Histopathology 1999;35: 477-478.

16 Rosivatz E, Becker I, Specht K et al. Differential expression of the epithelial-mesenchymal transition regulators snail, SIP1, and twist in gastric cancer. Am J Pathol 2002;161:1881-1891.

17 Fenoglio-Preiser CM, Wang J, Stemmermann GN et al. TP53 and gastric carcinoma: a review. Hum Mutat 2003;21:258-270.

18 Ando K, Oki E, Saeki H et al. Discrimination of p53 immunohistochemistry-positive tumors by its staining pattern in gastric cancer. Cancer Med 2015;4:75-83.

19 Truong CD, Feng W, Li W et al. Characteristics of Epstein-Barr virus-associated gastric cancer: a study of 235 cases at a comprehensive cancer center in USA. J Exp Clin Cancer Res 2009;28:14-9966-28-14.

20 Zhao J, Liang Q, Cheung KF et al. Genome-wide identification of Epstein-Barr virus-driven promoter methylation profiles of human genes in gastric cancer cells. Cancer 2013;119:304-312.

21 Hino R, Uozaki H, Inoue Y et al. Survival advantage of EBV-associated gastric carcinoma: survivin upregulation by viral latent membrane protein $2 \mathrm{~A}$. Cancer Res 2008;68:1427-1435.

22 Gulley ML. Genomic assays for Epstein-Barr viruspositive gastric adenocarcinoma. Exp Mol Med 2015; 47:e134

23 Gulley ML, Pulitzer DR, Eagan PA et al. Epstein-Barr virus infection is an early event in gastric carcinogenesis and is independent of bcl-2 expression and p53 accumulation. Hum Pathol 1996;27:20-27.

24 Kim SY, Park C, Kim HJ et al. Deregulation of immune response genes in patients with Epstein-Barr virusassociated gastric cancer and outcomes. Gastroenterology 2015;148:137-147.e9.

25 Grogg KL, Lohse CM, Pankratz VS et al. Lymphocyterich gastric cancer: associations with Epstein-Barr virus, microsatellite instability, histology, and survival. Mod Pathol 2003;16:641-651.

26 Sudo M, Chong JM, Sakuma K et al. Promoter hypermethylation of E-cadherin and its abnormal expression in Epstein-Barr virus-associated gastric carcinoma. Int J Cancer 2004;109:194-199.

27 Zazula M, Ferreira AM, Czopek JP et al. CDH1 gene promoter hypermethylation in gastric cancer: relationship to Goseki grading, microsatellite instability status, and EBV invasion. Diagn Mol Pathol 2006;15:24-29.

28 Kusano M, Toyota M, Suzuki H et al. Genetic, epigenetic, and clinicopathologic features of gastric carcinomas with the $\mathrm{CpG}$ island methylator phenotype and an association with Epstein-Barr virus. Cancer 2006;106:1467-1479.

29 Chang MS, Lee HS, Kim CW et al. Clinicopathologic characteristics of Epstein-Barr virus-incorporated gastric cancers in Korea. Pathol Res Pract 2001;197: 395-400.

30 Li S, Du H, Wang Z, Zhou L et al. Meta-analysis of the relationship between Epstein-Barr virus infection and clinicopathological features of patients with gastric carcinoma. Sci China Life Sci 2010;53:524-530.

31 Murphy G, Pfeiffer R, Camargo MC et al. Meta-analysis shows that prevalence of Epstein-Barr virus-positive gastric cancer differs based on sex and anatomic location. Gastroenterology 2009;137:824-833.

32 Camargo MC, Kim WH, Chiaravalli AM et al. Improved survival of gastric cancer with tumour Epstein-Barr virus positivity: an international pooled analysis. Gut 2014;63:236-243.

33 Cheng N, Hui DY, Liu Y et al. Is gastric lymphoepithelioma-like carcinoma a special subtype of EBVassociated gastric carcinoma? New insight based on clinicopathological features and EBV genome polymorphisms. Gastric Cancer 2015;18:246-255.

34 Song HJ, Srivastava A, Lee J et al. Host inflammatory response predicts survival of patients with Epstein-Barr virus-associated gastric carcinoma. Gastroenterology 2010;139:84-92.e2.

35 van Beek J, zur Hausen A, Klein Kranenbarg E et al. EBV-positive gastric adenocarcinomas: a distinct clinicopathologic entity with a low frequency of lymph node involvement. J Clin Oncol 2004;22:664-670.

36 Park S, Choi MG, Kim KM et al. Lymphoepitheliomalike carcinoma: a distinct type of gastric cancer. J Surg Res 2015;194:458-463.

37 Arai T, Sakurai U, Sawabe M et al. Frequent microsatellite instability in papillary and solid-type, poorly differentiated adenocarcinomas of the stomach. Gastric Cancer 2013;16:505-512.

38 Wang K, Yuen ST, Xu J et al. Whole-genome sequencing and comprehensive molecular profiling identify new driver mutations in gastric cancer. Nat Genet 2014;46:573-582.

39 Chung YJ, Kim KM, Choi JR et al. Relationship between intratumor histological heterogeneity and genetic abnormalities in gastric carcinoma with microsatellite instability. Int J Cancer 1999;82:782-788.

40 Lee HS, Choi SI, Lee HK et al. Distinct clinical features and outcomes of gastric cancers with microsatellite instability. Mod Pathol 2002;15:632-640.

41 Seo HM, Chang YS, Joo SH et al. Clinicopathologic characteristics and outcomes of gastric cancers with the MSI-H phenotype. J Surg Oncol 2009;99: 143-147.

$42 \mathrm{Gu}$ M, Kim D, Bae Y et al. Analysis of microsatellite instability, protein expression and methylation status of hMLH1 and hMSH2 genes in gastric carcinomas. Hepatogastroenterology 2009;56:899-904.

43 Corso G, Pedrazzani C, Marrelli D et al. Correlation of microsatellite instability at multiple loci with long-term survival in advanced gastric carcinoma. Arch Surg 2009;144:722-727.

44 Beghelli S, de Manzoni G, Barbi S et al. Microsatellite instability in gastric cancer is associated with better prognosis in only stage II cancers. Surgery 2006;139: 347-356.

45 Leung SY, Yuen ST, Chung LP et al. hMLH1 promoter methylation and lack of hMLH1 expression in sporadic gastric carcinomas with high-frequency microsatellite instability. Cancer Res 1999;59:159-164.

46 Hudler P. Genetic aspects of gastric cancer instability. Scientific World J 2012;2012:761909.

47 Liu XP, Tsushimi K, Tsushimi M et al. Expression of p53 protein as a prognostic indicator of reduced survival time in diffuse-type gastric carcinoma. Pathol Int 2001;51:440-444. 
48 Tamura G, Sato K, Akiyama S et al. Molecular characterization of undifferentiated-type gastric carcinoma. Lab Invest 2001;81:593-598.

49 Mateus AR, Seruca R, Machado JC et al. EGFR regulates RhoA-GTP dependent cell motility in E-cadherin mutant cells. Hum Mol Genet 2007;16:1639-1647.

50 Deplazes J, Fuchs M, Rauser S et al. Rac1 and rho contribute to the migratory and invasive phenotype associated with somatic E-cadherin mutation. Hum Mol Genet 2009;18:3632-3644.

$51 \mathrm{Xu} \mathrm{XT}$, Song QB, Yao Y et al. Inhibition of RhoA/ ROCK signaling pathway promotes the apoptosis of gastric cancer cells. Hepatogastroenterology 2012;59: 2523-2526.

52 Yuan CX, Zhou ZW, Yang YX et al. Danusertib, a potent pan-aurora kinase and ABL kinase inhibitor, induces cell cycle arrest and programmed cell death and inhibits epithelial to mesenchymal transition involving the PI3K/akt/mTOR-mediated signaling pathway in human gastric cancer AGS and NCI-N78 cells. Drug Des Dev Ther 2015;9:1293-1318.

53 Gamboa-Dominguez A, Dominguez-Fonseca C, Chavarri-Guerra $\mathrm{Y}$ et al. E-cadherin expression in sporadic gastric cancer from Mexico: exon 8 and 9 deletions are infrequent events associated with poor survival. Hum Pathol 2005;36:29-35.

54 Carpenter PM, Al-Kuran RA, Theuer CP. Paranuclear E-cadherin in gastric adenocarcinoma. Am J Clin Pathol 2002;118:887-894.

55 Handschuh G, Candidus S, Luber B et al. Tumourassociated E-cadherin mutations alter cellular morphology, decrease cellular adhesion and increase cellular motility. Oncogene 1999;18:4301-4312.

56 Ascano JJ, Frierson H Jr, Moskaluk CA et al. Inactivation of the E-cadherin gene in sporadic diffuse-type gastric cancer. Mod Pathol 2001;14:942-949.

57 Gabbert HE, Muller W, Schneiders A et al. The relationship of p53 expression to the prognosis of 418 patients with gastric carcinoma. Cancer 1995;76: 720-726.

$58 \mathrm{Kim}$ JP, Oh ST, Hwang TS et al. The prognostic significance of c-erbB-2 and p53 protein expressions in gastric carcinoma-a multivariate analysis of prognostic factors. J Korean Med Sci 1994;9:248-253.

59 Monig SP, Eidt S, Zirbes TK et al. P53 expression in gastric cancer: clinicopathological correlation and prognostic significance. Dig Dis Sci 1997;42: 2463-2467.

60 Motojima K, Furui J, Kohara N et al. Expression of p53 protein in gastric carcinomas is not independently prognostic. Surgery 1994;116:890-895.

61 Sasaki I, Yao T, Nawata $\mathrm{H}$ et al. Minute gastric carcinoma of differentiated type with special reference to the significance of intestinal metaplasia, proliferative zone, and p53 protein during tumor development. Cancer 1999;85:1719-1729.

62 Bang YJ, Van Cutsem E, Feyereislova A et al. Trastuzumab in combination with chemotherapy versus chemotherapy alone for treatment of HER2-positive advanced gastric or gastro-oesophageal junction cancer (ToGA): A phase 3, open-label, randomised controlled trial. Lancet 2010;376:687-697. 